\title{
STUDY OF RENAL FAILURE IN MALARIA
}

Girish Pamappa Vakrani1, Nambakam Tanuja Subramanyam², Pawan Kumar Perugu ${ }^{3}$

${ }^{1}$ Assistant Professor, Department of Nephrology, Vydehi Institute of Medical Sciences and Research Center, Bengaluru.

${ }^{2}$ Assistant Professor, Department of General Medicine, Vydehi Institute of Medical Sciences and Research Center, Bengaluru.

3Junior Resident, Department of General Medicine, Vydehi Institute of Medical Sciences and Research Center, Bengaluru.

\section{ABSTRACT}

Renal failure is a serious complication of malaria, with a mortality of 14 to $33 \%$. In view of the significant morbidity and mortality due to acute renal failure in malaria, there is need to identify patients at an early stage and to intensify care given to reduce morbidity and mortality.

\section{AIMS}

- To evaluate the clinical profile of Acute Renal Failure (ARF) in malaria.

- To evaluate the factors associated with adverse outcome, relation of severity of renal impairment on final outcome in patients with ARF due to malaria.

\section{MATERIAL AND METHODS}

This study was conducted at a tertiary care hospital over a period of 12 months.

\section{STUDY DESIGN}

- Type of study: Prospective Analytical, Observational Study.

- Sample Size: 50 patients admitted to ICU, Kidney Unit, and the Medicine Wards with Malaria and ARF.

\section{Inclusion Criteria}

Clinically screened patients with evidence of malarial parasites in the blood smears or by antigen detection with clinical features or biochemical evidence of acute renal failure.

\section{Exclusion Criteria}

- Presence of any disease or condition leading to ARF or affecting the outcome of malarial ARF.

- Other causes of Fever, Jaundice and Oliguria, like Leptospirosis, Dengue.

\section{METHODOLOGY}

Fifty patients who fulfilled the inclusion criteria were interrogated with regards to the complaints, clinical signs. Blood tests were sent on admission. Details were recorded as per the clinical proforma. The patients were followed until their discharge/death.

\section{RESULTS}

Oliguria was present in only $30 \%$ of patients. $30 \%$ of patients received haemodialysis. The mortality was $12 \%$ for severe renal failure. On Univariate analysis, Acidosis and Cerebral malaria were highly significant predictors of mortality. Other significant predictors were Renal failure, Oliguria, Shock, DIC, Hyperparasitemia, Leukocytosis (TLC). On Multivariate analysis, Oliguria, Cerebral malaria, Acidosis, Shock and two or more complications were the independent predictors of mortality.

\section{CONCLUSIONS}

- Acute renal failure was an important and life threatening complication of falciparum malaria having a male preponderance.

- Hyperbilirubinemia, Cerebral malaria, Metabolic acidosis, ARDS, DIC and Shock were the complications commonly associated with ARF in malaria.

- Oliguria, Cerebral malaria, Acidosis, Shock, TLC proved to be independent predictors of mortality.

\section{KEYWORDS}

Malaria, Renal failure, Oliguria, Hemodialysis.

HOW TO CITE THIS ARTICLE: Vakrani GP, Subramanyam NT, Perugu PK. Study of renal failure in malaria. J Evolution Med Dent Sci 2016;5(1):04-08, DOI: 10.14260/jemds/2016/2

Financial or Other, Competing Interest: None.

Submission 08-12-2015, Peer Review 09-12-2015,

Acceptance 29-12-2015, Published 01-01-2016.

Corresponding Author:

Girish Pamappa Vakrani,

A-29, Vydehi Hospital Staff Quarters,

\#82, EPIP Area, Whitefield,

Bengaluru-560066.

E-mail:drvakranis@gmail.com,dr_vakranis@yahoo.co.in DOI:10.14260/jemds/2016/2

\section{INTRODUCTION}

Malaria is caused by four species of the genus Plasmodium namely, Plasmodium vivax, Plasmodium falciparum, Plasmodium malariae and P. ovale. As per World Health Organisation, the major manifestations of severe malaria are cerebral malaria, severe anemia, jaundice, Acute Renal Failure (ARF), Acute Respiratory Distress Syndrome (ARDS), shock, disseminated major bacterial pathogens being isolated and 
intravascular coagulation (DIC), convulsions, haemoglobinuria, impaired consciousness. ${ }^{1}$ These occur mostly with Plasmodium falciparum malaria. Occurrences of acute renal failure in severe falciparum malaria is quite common in southeast Asia. ${ }^{2}$ and Indian subcontinent. ${ }^{3}$ Renal failure is a serious complication of malaria, with a reported total mortality of 14 to $33 \% .4,5,6$

In view of the significant morbidity and mortality due to acute renal failure in malaria, there is an acute need to identify patients at an early stage and to intensify care given to these patients so that the burden of morbidity and mortality is reduced. This study is undertaken to evaluate the clinical profile and outcome of acute renal failure in malaria, admitted in our institute from January 2012 to December 2012.

\section{MATERIAL AND METHODS}

This study was conducted at a tertiary care hospital over a period of 12 months.

\section{AIMS AND OBJECTIVES}

- To evaluate the clinical profile of Acute Renal Failure in malaria.

- To evaluate the factors associated with adverse outcome, relation of severity of renal impairment on final outcome in patients with ARF due to malaria.

\section{Study Period}

January 2012 to December 2012.

\section{Selection of Cases}

Those patients admitted to ICU, kidney unit and the medicine wards in our institute with malaria and ARF were included in the study.

\section{Study Design}

- Type of Study: prospective analytical, observational study.

- Sample Size: 50 cases.

\section{Inclusion Criteria}

Clinically screened patients aged more than 18 years with evidence of malarial parasites in the blood smears or by antigen detection with clinical features or biochemical evidence of acute renal failure as follows:

1. Fever, nausea/vomitings, oliguria/anuria sometimes polyuria, jaundice, abdominal pain/tenderness, splenomegaly, shock, dyspnoea, altered sensorium, rarely convulsions.

2. Urine output less than $400 \mathrm{ml} /$ day despite of rehydration.

3. Serum creatinine more than $2 \mathrm{mg} / \mathrm{dl}$.

\section{Exclusion Criteria}

- Age less than 18 years.

- Presence of any disease or condition leading to ARF or affecting the outcome of malarial ARF.

- Any abnormalities of kidney on ultrasonography.

- Other causes of fever jaundice and oliguria, like leptospirosis, dengue.

\section{METHODOLOGY}

Fifty patients who fulfilled the inclusion criteria were enrolled in the study. Patients who fulfilled the inclusion criteria were thoroughly interrogated with regards to the presenting complaints like fever, jaundice, urine output, swelling of the body, breathlessness, bleeding tendency, altered sensorium, convulsions, etc. Vital parameters like temperature, pulse rate, blood pressure, respiratory rate were recorded. Clinical signs at admission like pallor, icterus, oedema, bleeding manifestations were noted and thorough systemic examination was done. The Glasgow coma score was also calculated. Blood investigations like peripheral smears, complete blood count, urea and creatinine levels, total bilirubin, SGOT, SGPT, blood glucose levels, electrolytes, arterial blood gases, were sent on admission. Parasite index was calculated for patients having positive peripheral smear as the number of parasites present per 100 red cells.

Details of treatment received by the patient before admission (At primary health centres) as well as in our hospital were recorded as per the clinical proforma. The patients were followed until their discharge/death and their outcome was noted as either Discharged (D) or Expired (E).

\section{RESULTS}

In our study, $35(70 \%)$ patients had manifestation of severe malaria as per WHO. The observations made in our study were as follows:

1. The age of these 50 patients were over a range from 18 years to 60 years. The mean age of the patients in our study was $32.48 \pm 4.35$ years.

2. Of these 50 patients, 43 (86\%) patients were males.

3. All 50 presented with fever with chills and rigors. The other presenting complaints were vomiting 29 (58\%), decreased urine output in 22 (44\%), altered sensorium in $18(36 \%)$, yellowness of eyes/dark yellow urine in 15 (30\%), Convulsions in 11 (22\%), breathlessness in 10 (20\%) and bleeding tendencies in 6 (12\%).

4. Pallor was the most dominant sign present in 37 (74\%), followed by Splenomegaly in 26(52\%), Icterus in 21 (42\%), pedal edema in 16 (32\%), Hepatomegaly in 15 (30\%), Low GCS in 12 (24\%) and Hepatosplenomegaly in $10(20 \%)$. Bleeding tendency in the form of bleeding gums or hematuria in $6(12 \%)$ and Hypotension in $5(10 \%)$ were rare observations.

5. $47(94 \%)$ patients had their HRP-2 test positive. While only $23(46 \%)$ of these 50 patients had malarial parasites detected on their peripheral smear. In these 23 patients with peripheral smear positive for malaria, $16(32 \%)$ of the patients had only Falciparum in their peripheral smear, Vivax was seen in $05(10 \%)$ and both plasmodium falciparum and vivax in 02 (04\%).

6. $34(68 \%)$ patients had normal output i.e. $24 \mathrm{hr}$. urine output $\geq 400 \mathrm{ml}$. Anuria was rare and present in only $1(2 \%)$ patient. The mean urine output was $691.0 \pm 141.8 \mathrm{ml}$.

7. Renal failure was divided into mild, moderate and severe depending upon the serum creatinine levels. 25 (50\%) had mild renal failure, moderate renal failure was seen in 14 (28\%) and severe renal failure was noted in 11 (22\%).

8. Proteinuria $>300 \mathrm{mg} /$ day was noted in $20(40 \%)$ patients. Hemoglobinuria was seen in only $07(14 \%)$ cases.

9. Moderate anemia [Hemoglobin: 07-10gm/dl] in 36 (72\%), Severe anemia [Hemoglobin $<07 \mathrm{gm} / \mathrm{dl}$ ] in $03(06 \%)$. The mean WBC count was $9830.83 \pm 1285.5$ per $\mathrm{mm}^{3}$. Leukocytosis with total WBC count $>13,000 / \mathrm{mm}^{3}$ in 08 (16\%) and $11000-13000 / \mathrm{mm}^{3}$ in $09(18 \%)$. The mean platelet count was $1.14 \pm 0.25 \quad \mathrm{lakh} / \mathrm{mm}^{3}$. Thrombocytopenia [Platelet count $<1.5 \mathrm{lakh} / \mathrm{mm}^{3}$ ] was seen in $37(74 \%)$ of patients, severe thrombocytopenia 
[Platelet count $<0.5 \mathrm{lakh} / \mathrm{mm}^{3}$ ] in $13(26 \%)$. The mean Prolonged Prothrombin time was $14.84 \pm 1.03$ sec. mildly prolonged prothrombin time [12 to $15 \mathrm{sec}$ ] in 33 (66\%), Prolonged Prothrombin time [ $>15 \mathrm{sec}]$ in 16 (32\%).

10. The mean S. bilirubin was $2.93 \pm 0.61 \mathrm{mg} / \mathrm{dl}$. Hyperbilirubinemia [S. bilirubin $>3 \mathrm{mg} / \mathrm{dL}$ ] was present in $21(42 \%)$. The mean serum ALT was $53.37 \pm 49.63 \mathrm{IU} / \mathrm{L}$. The mean Serum AST was 55.5 $\pm 49 / 35$ IU/L. Serum ALT [Serum ALT $>120 \mathrm{IU} / \mathrm{L}$ ] was noted in $04(08 \%)$ of cases and elevated serum AST [serum AST $>120 \mathrm{IU} / \mathrm{L}$ ] in 04 $(08 \%)$ of cases.

11. The mean arterial $\mathrm{pH}$ was $7.29 \pm 0.02$. Arterial $\mathrm{pH}<7.25$ was seen in $15(30 \%)$ of patients, mean plasma Bicarbonate was $17.02 \pm 1.81 \mathrm{mmol} / \mathrm{L}$. Among these serum bicarbonate $<15 \mathrm{mmol} / \mathrm{L}$ was noted in $14(28 \%)$ of patients.

12. The mean serum Sodium was $133.80 \pm 2.61 \mathrm{meq} / \mathrm{l}$. Hyponatremia [Sr. $\left.\mathrm{Na}^{+}<135 \mathrm{meq} / \mathrm{l}\right]$ was seen in 27 (54\%) cases. Hypernatremia $\left[\mathrm{Sr} . \mathrm{Na}^{+}>145 \mathrm{meq} / \mathrm{l}\right]$ was uncommon, seen in $02(04 \%)$ cases. The mean serum Potassium was $4.49 \pm 0.25 \mathrm{meq} / \mathrm{dl}$. In this study hypokalemia [Sr. $\left.\mathrm{K}^{+}<3.5 \mathrm{meq} / \mathrm{dl}\right]$ was seen in $03(06 \%)$ patients, while hyperkalemia $\left[\mathrm{Sr} . \mathrm{K}^{+}>5 \mathrm{meq} / \mathrm{dl}\right]$ in 08 (16\%) patients.

13. Among the factors associated in development of ARF. Hyperbilirubinemia was common, present in 21 (42\%) of cases. While DIC, hypotension and hemolysis were rare, being present in $06(12 \%), 05(10 \%)$ and $03(06 \%)$ cases respectively.

14. It was noted that $12(24 \%)$ patients received artesunate and $16(32 \%)$ patients received quinine only. While the combination antimalarial drugs artesunate and clindamycin was given to $8(16 \%)$ of patients

15. $15(30 \%)$ of patients received hemodialysis. Rest of the 35 (70\%) patients were managed conservatively.

16. Out of the 50 patients, 44 (88\%) survived, while the rest of the $06(12 \%)$ of the patients succumbed to the disease. The mean duration of stay for the patients who recovered was $5.66 \pm 0.76$. Death occurred at a mean time of $4.38 \pm 0.57$ days (Range 1-6 days) after admission. The overall mortality in our study was $12 \%$ ( 06 patients out of 50 died) mortality was seen in patients with severe renal failure. Mortality in male patients was higher than the female patients, though the difference was statistically not significant.

17. Thus, mean urea, creatinine and serum potassium levels were significantly higher in patients who died as compared to those who survived (Table 1).

18. More than one complication was present in 34 (77\%) patients in the survivor group and in $6(100 \%)$ patients in the non-survivor group. Patients who had more than one complication mortality were significantly greater.

On univariate analysis (Table 2), significant predictors of mortality were: Cerebral malaria and Acidosis. At the end of multivariate analysis (Table 3), Oliguria, cerebral malaria, acidosis, DIC, shock and two or more complication were the independent predictors of mortality.

\section{DISCUSSION}

Acute Renal Failure (ARF) occurs as a complication of P. Falciparum malaria in $57 \%$ to $60 \%{ }^{7}$, and the mortality in these cases may be between 14 to $33 \% .4,5,6$

\section{Diagnosis of Malaria}

In the 23 patients with peripheral smear positive for malaria, Plasmodium falciparum was seen in 16 (92\%). Prakash et al (2002) in a study of ninety-four patients of acute renal failure (ARF) complicating malaria over 5 years noted that Plasmodim falciparum and P.vivax were responsible for ARF in $76(80.9 \%)$ and 11 (11.7\%) patients respectively. ${ }^{8}$

\section{DIAGNOSIS OF RENAL FAILURE}

\section{Serum Creatinine}

Majority of patients 25 (50\%) had mild renal failure. Mehta et al. (2001) in a study diagnosed ARF on the basis of serum creatinine $>1.5 \mathrm{mg} / \mathrm{dl}$. They found 24 patients of malarial ARF over a 2 year period. Mild renal failure included serum creatinine $<2 \mathrm{mg} / \mathrm{dl}$, moderate renal failure included serum creatinine $2-5 \mathrm{mg} / \mathrm{dl}$ and severe renal failure included serum creatinine $>5 \mathrm{mg} / \mathrm{dl}$. They noted $75 \%$ patients had severe renal failure, $25 \%$ had moderate renal failure and none had mild renal failure. ${ }^{9}$

\section{Urine Output}

Oliguria was noted in 16 (32\%) patients. Mehta et al. (2001) noted 14 (58.33\%) patients had non-oliguric ARF. ${ }^{9}$ In the present study in the oliguric group the mean serum creatinine value was $5.40 \mathrm{mg} / \mathrm{dl}$, while in the non-oliguric group the mean serum creatinine value was $2.80 \mathrm{mg} / \mathrm{dl}$. Thus oliguric patients had more renal impairment.

\section{Urine Examination}

Proteinuria $>300 \mathrm{mg} /$ day was noted in $20(40 \%)$ of patients. Mehta et al (2001) noted Proteinuria (2+) in $28.26 \%$, and microscopic haematuria in $21.74 \%$ patients. ${ }^{10}$ Age distribution of patients: Patients age ranged from 18 to 60 years with average age was $32.48 \pm 4.32$ years. Manan et al. (2006) studied patients who ranged in age from 16-65 years with a mean $32 \pm 12.61$ years. ${ }^{10}$

\section{SEX DISTRIBUTION OF STUDY SUBJECT}

There was a male preponderance. Manan et al. (2006) in a study noted the male to female ratio was 3.6:1.

\section{Clinical Profile}

Symptom profile of study subjects: All 50 cases presented with fever with chills and rigors. Mehta et al. (2001) found the majority $(91.66 \%)$ presented with fever followed by altered sensorium in $41.66 \%$ decreased urine output in $41.66 \%$, convulsions in $8.33 \%$, vomiting was present in $33.33 \%$ and loose stools in $12.5 \%$ of patients. ${ }^{9}$ Thus, most of these finding are consistent with other studies.

\section{Clinical Signs}

Pallor was the most dominant sign, present in 37 (74\%). Prakash et al. (2002) in a study, noted splenomegaly in $26.0 \%$, hepatomegaly in $10.06 \%$ and hypotension in $32 \%$ patients. $^{8}$

\section{INVESTIGATIONS}

\section{Hematological Profile}

Severe anaemia was seen in $3(6 \%)$, Leukocytosis with total WBC count $>13.000 / \mathrm{mm}^{3}$ in $08(16 \%)$, Thrombocytopenia [Platelet count $<1.5 \mathrm{lakh} / \mathrm{mm}^{3}$ ] in $24(48 \%)$ of patients, Prolonged prothrombin time [12-15 sec] in $33(66 \%)$ of patients. Prakash et al. (2002) noted thrombocytopenia 
$12.76 \%$ patients. $^{8}$ Naqvi et al. (2003) found moderate reduction in haemoglobin was common. ${ }^{11}$ Thrombocytopenia, $<150,000 / \mathrm{mm}^{3}$, was present in 87 patients by Naqvi et al. (2003).

In a study by Wilairatana (1999), it was noted total WBC count $>10,000 / \mathrm{mm}^{3}$ was seen in $60.7 \%$ of patients. ${ }^{12}$

Liver function tests: Hyperbilirubinemia was present in 21 (42\%). Hyperbilirubinemia was present in 31 (32.97\%) patients in a study by Prakash et al. (2002). ${ }^{8}$

\section{Metabolic Acidosis}

Metabolic acidosis was noted in 14 (28\%) of patients. Manan et al. (2006) in a study found metabolic acidosis in $19.17 \%$ patients. ${ }^{10}$

\section{Hypoglycaemia}

Hypoglycaemia was noted in $04(08 \%)$ of patients in the present study. Prakash et al. (1996) found hypoglycaemia in $11.5 \%$ of patients. ${ }^{3}$

\section{Electrolyte Imbalance}

It was noted that hyponatremia was common, seen in 27 (54\%) cases. Hyponatremia was found in $57.7 \%$ of cases by Prakash et al. (1996). ${ }^{3}$

Complications of severe malaria and risk factors for ARF: Cerebral malaria (GCS $<11$ ) was present in $12(24 \%)$. Acidosis was present in $15(30 \%)$ patients, ARDS was present in 9 (18\%), Severe anaemia was present in 04 (08\%), Hypoglycaemia was present in $4(8 \%)$.

Prakash et al. (2002) in a study of 94 patients of acute renal failure complicating malaria noted that multiple etiologic factors were contributing to the development of ARF and these included: Volume depletion 49 (51\%), intravascular hemolysis 37 (39.4\%), heavy parasitemia 34 (35\%), hyperbilirubinemia $31(33 \%)$, hypotension 29 (30.9\%), sepsis $9(9.6 \%)$ and DIC 7 $(7.4 \%){ }^{8}$

\section{Antimalarial Treatment}

We noted that $12(24 \%)$ patients received artesunate and 16 (32\%) patients received quinine only. A large randomized comparison of intra venous artesunate and quinine in 1461 patients with multiple complications including ARF by Dondorp et al. (2005) in Asia showed a significant survival benefit with artesunate. Mortality was $22 \%$ with quinine as compared with $15 \%$ with artesunate, a risk reduction of $34.7 \% .^{13}$ They found no significant differences in the outcome and complications among the different drug regimens of 112 study patients. ${ }^{12}$

In the present study, it was noted out of 6 patients who died received combination antimalarial drugs. Mortality was $0.03 \%$ in patients receiving a single anti-malarial drug and was $23.52 \%$ in patients receiving a combination anti-malarial drug. It was noted that patients with severe malaria usually tend to receive combination therapy. This may explain the higher mortality seen in group receiving combination therapy.

\section{Renal Replacement Therapy}

$15(30 \%)$ of patients received haemodialysis. Mehta et al. (2001) study found 92\% cases required dialysis of which 8 required haemodialysis. ${ }^{9}$

\section{Supportive Treatment}

Diuretics were given to 20 (40\%) of patients. Blood or blood components were given to 25 (50\%) of patients. Review by Bagshaw (2007) comparing loop diuretics with control in the management of ARF did not notice any association of diuretic use with reduction in mortality or requirement for renal replacement therapy. However, use of diuretics was associated with shorter duration of renal replacement therapy and increased urine output. ${ }^{14}$

\section{Outcome}

The mortality was $12 \%$ for severe renal failure. Mehta et al. (2001) in a study from Mumbai diagnosed ARF on the basis of serum creatinine more than $1.5 \mathrm{mg} / \mathrm{dl}$. In their study $75 \%$ patients had severe renal failure, $25 \%$ had moderate and none of them had minor renal failure. They noticed mortality was 29\% malarial ARF. ${ }^{9}$ The relatively low mortality in the present study may be attributed to the high proportion (50\%) of patients with serum creatinine less than $3 \mathrm{mg} / \mathrm{dl}$.

\section{Statistical Analysis \\ Univariate Analysis}

On univariate analysis predictors of mortality in the present study were as follows: Highly significant predictors of mortality were: Cerebral malaria, Arterial pH and Plasma bicarbonate $(\mathrm{p}<0.001)$. Other significant predictors of mortality were: Oliguria, Shock, Disseminated intravascular coagulation, Total leucocyte count, Blood urea and Serum creatinine.

\section{Multivariate Analysis}

On multivariate analysis predictors of mortality were as follows: Oliguria, Cerebral malaria, Acidosis, TLC, Shock and presence of two or more complications apart from renal failure were the independent predictors of mortality. According to a study by Manan et al. (2006), Serum creatinine Leukocytosis, Hyperbilirubinemia, Cerebral malaria, DIC, Metabolic acidosis were the main causes of mortality in their patients. ${ }^{10}$

\section{CONCLUSIONS}

- Acute renal failure was an important and life threatening complication of falciparum malaria having a male preponderance.

- Non-oliguric renal failure was the most common pattern of renal failure.

- Other clinical manifestations being altered sensorium, jaundice, breathlessness and bleeding tendency.

- Hyperbilirubinemia, Cerebral malaria, Metabolic acidosis, ARDS, DIC and Shock were the complications commonly associated with ARF in malaria.

- Oliguria, Cerebral malaria, Acidosis, TLC, Shock and two or more complications proving to be independent predictors of mortality.

\section{Limitations of the Study}

- In the present study, the sample size was small.

- Majority of the patients had non-oliguric and mild-tomoderate renal failure. This could be responsible for the relatively low mortality. 
- We evaluated only those patients who are admitted, so we missed those patients who died before reaching the hospital.

- It was not possible to evaluate the antimalarial treatment given to the patients before they were admitted in our hospital.

\begin{tabular}{|c|c|c|c|c|}
\hline $\begin{array}{l}\text { Sr. } \\
\text { No. }\end{array}$ & Parameter & $\begin{array}{l}\text { Survivors } \\
(\mathrm{n}=44)\end{array}$ & $\begin{array}{c}\text { Non- } \\
\text { Survivors } \\
(n=06)\end{array}$ & $\begin{array}{c}\text { p- } \\
\text { value }\end{array}$ \\
\hline 1 & $\begin{array}{l}\text { Mean Blood } \\
\text { urea }(\mathrm{mg} / \mathrm{dl})\end{array}$ & $94.5 \pm 22.37$ & $\begin{array}{c}175.83 \pm 107 \\
09\end{array}$ & $0.0021^{*}$ \\
\hline 2 & $\begin{array}{c}\text { Mean Serum } \\
\text { Creatinine } \\
(\mathrm{mg} / \mathrm{dl})\end{array}$ & $3.43 \pm 0.65$ & $7.13 \pm 3.10$ & $0.0046^{*}$ \\
\hline 3 & $\begin{array}{l}\text { Mean Serum } \\
\text { sodium } \\
(\mathrm{meq} / \mathrm{dl})\end{array}$ & $134.11 \pm 2.87$ & $131.55 \pm 8.05$ & 0.3149 \\
\hline 4 & $\begin{array}{l}\text { Mean Serum } \\
\text { potassium } \\
(\mathrm{meq} / \mathrm{dl})\end{array}$ & $4.35 \pm 0.21$ & $5.48 \pm 1.12$ & 0.0119 \\
\hline \multicolumn{5}{|c|}{$\begin{array}{c}\text { Table 1: Table showing RFT and } \\
\text { mortality in Study Subjects }(n=50)\end{array}$} \\
\hline
\end{tabular}

\begin{tabular}{|c|c|}
\hline Parameter & P-value \\
\hline Oliguria & 0.014 \\
\hline $\begin{array}{c}\text { Mean Serum Creatinine } \\
(\mathrm{mg} / \mathrm{dl})\end{array}$ & 0.0037 \\
\hline Mean Blood Urea (mg/dl) & 0.01196 \\
\hline Mean WBC count (x103/L) & 0.00553 \\
\hline Cerebral malaria & $<0.001$ \\
\hline Acidosis & $<0.001$ \\
\hline DIC & 0.0048 \\
\hline Shock & 0.01 \\
\hline $\begin{array}{c}\text { Two or more complications } \\
\text { apart from renal failure }\end{array}$ & 0.002 \\
\hline \multicolumn{2}{|c|}{ Table 2: Showing Univariate Analysis } \\
of factors predicting mortality
\end{tabular}

\begin{tabular}{|c|c|}
\hline Parameter & P-value \\
\hline Oliguria & 0.0012 \\
\hline Mean Serum Creatinine (mg/dl) & 0.234 \\
\hline Mean Blood Urea (mg/dl) & 0.0116 \\
\hline Mean WBC count (x103/L) & 0.0049 \\
\hline Cerebral malaria & $<0.001$ \\
\hline Acidosis & $<0.001$ \\
\hline DIC & 0.0063 \\
\hline Shock & 0.0032 \\
\hline $\begin{array}{c}\text { Two or more complications apart } \\
\text { from renal failure }\end{array}$ & $<0.001$ \\
\hline \multicolumn{2}{|c|}{ Table 3: Showing Multivariate } \\
Analysis of factors predicting mortality \\
\hline \multicolumn{2}{|c|}{}
\end{tabular}

\section{BIBLIOGRAPHY}

1. World Health Organisation. Severe falciparum malaria. Trans R Soc Trop Med Hyg 2000;94:S1-S90.

2. Sitprija V. Nephrology forum. Nephropathy in falciparum malaria. Kidney int 1988;34:966.

3. Prakash J, Gupta A, Kumar O, Rout SB, Malhotra V and Srivastava PK. Acute renal failure in falciparum malariaincreasing prevalence in some area of India- A need for awareness. Nephrol dial Transplant 1996;11(12:24142416).

4. Naqvi R, Ahmad E, Akhtar F, et al. Predictors of outcome in malarial renal failure. Renal fail 1996;18(4):685-688.

5. Weber MW, Boker K, Horstmann RD, et al. Renal failure is a common complication in non-immune Europeans with Plasmodium falciparum malaria. Trop Med Parasitol 1991;42(2):115-118.

6. William J Stone, MD; James E Hanchett; M A J James H; et al. Acute renal insufficiency due to Falciparum malaria. Arch Intern Med 1972;129(4):620-628.

7. Barsoum RS. Malaria acute renal failure. J Am Soc Nephrol 2000;11:2147-54.

8. Prakash J, Singh AK, Gujrati S, et al. Acute renal failure in malaria: Changing trends. Indian J Nephrol 2002;12:113-117.

9. Mehtha KS, Halankar AR, Makwana PD, et al. Severe acute renal failure in malaria. J Postgrad Med 2001;47:24-26.

10. Abdul Manan J, Ali H, Lal M. Acute renal failure associated with malaria. J Ayub Med Coll Abbottabad 2006;18:47-52.

11. Naqvi R, Ahmad E, Akhtar F, et al. Outcome in severe acute renal failure associated with malaria. Nephrol Dial Transplant 2003;18:1820-3.

12. Wilairatana P, Westerlund EK, Aursudkij B, Vannapan S, Krudsood S, Viriyavejakul P, et al. Treatment of malaria acute renal failure by hemodialysis. Am J Trop Med Hyg 1999;60:233-7.

13. Dondrop A, Nosten F, Stepnieswaka K, et al. Artesunate versus Quinine for treatment of severe falciparum malaria: a randomized trial. Lancet 2005;366:717-25.

14. Bagshaw SM, Delaney A, Haase M, et al. Loop diuretics in the management of acute renal failure: a systematic review and meta-analysis. Crit Care Resusc 2007;9:60-8. 